\title{
Research on the Cultivation and Promotion of Practical Innovation Ability of Professional Degree Graduates in the New Situation
}

\author{
Zhang Jian \\ College of Aerospace Engineering \\ Nanjing University of Aeronautics and Astronautics \\ Nanjing, China \\ jianzhang78@126.com
}

Ye Xin

Chengxian College

Southeast University

Nanjing, China

yexinadd@163.com

\author{
Shen Xing \\ College of Aerospace Engineering \\ Nanjing University of Aeronautics and Astronautics \\ Nanjing, China \\ shenx@nuaa.edu.cn \\ Lin Jing \\ Institute of Civil Engineering \\ Tongji University \\ Shanghai, China \\ linjingseu@126.com
}

\begin{abstract}
Full-time professional graduate degree education is a type of education advocated by the country nowadays. It is produced to meet the continuous development of China's graduate education system and is a basic part of the national innovation system. Its core task lies in cultivating students' innovative consciousness. The application type of compounding high level in engineering technology and engineering management talents with innovative capabilities and social practice capabilities is necessarily needed. In order to improve postgraduates' innovation ability, social practice ability and their competitiveness in employment and entrepreneurship, it is finally concluded that we can try to establish a practice-oriented training model for professional graduate students with innovative awareness and innovative abilities so that the trained personnel can meet the needs of innovative engineering talents in the economic society.
\end{abstract}

Keywords-Professional Degree Graduates; New Situation; Practical Innovation Ability; Cultivation; Promotion

\section{INTRODUCTION}

Academic master's education focuses on the cultivation of teaching and research talents. The type of degree conferred is mainly an academic degree; the professional master's degree is a new master's degree added by the state to overcome the lack of academic masters, and it is cultivated by the current market of applied talents. The professional master's innovative thinking and consciousness are prerequisites for the ability to innovate and practice [1]. At present, the majority of graduate students after graduating are directly entering the enterprise through colleges and universities. The time spent in school is relatively long, and they lack the ability to think independently, think creatively, and solve problems. Therefore, it is urgent to carry out the analysis of the factors constraining the graduates' creative abilities, and to explore the training strategies and measures for the training of postgraduates' awareness of innovation and the improvement of their innovative abilities. Universities should establish a mentor team with a high academic level, a certain professional background and rich practical experience [2]. Under the ever-changing educational environment and background, it is possible to implement a school-based tutor-led, off-campus enterprise tutor as a fulltime professional master training system that assists in the practice of guidance. Therefore, the innovation of this project is also manifested in exploring how to establish a better quality training system in order to meet the needs of China's talent cultivation for professional graduate students, and at the same time meet the employer's demand for high-level practical and innovative engineering [3]. Since the Ministry of Education issued in 2009 to announce that China has started to recruit full-time professional graduates, it has made major developments after many years of exploration and efforts by the national and graduate training units. The emergence of fulltime professional degree graduate students aims to promote the strategic adjustment of graduate education structure, alleviate the problem that the training quality and specifications of talents are inconsistent with the needs of the social industry for high-level talents, and synchronize talent cultivation with national construction and social needs [4]. It is connected to meet the needs of socialist modernization for high-end professionals. In order to achieve this goal, colleges and universities must ensure the quality of full-time professional graduate degree training, and in particular, ensure that qualified personnel are able to adapt to the requirements of social development and meet the needs of society. Professional degree is relative to academic degree [5]. Professional degree is the demand for talents for specific social occupations. It is a type of degree established for the cultivation of high-end professional talents in the society [6]. It has a combination of professional and academic nature, and specific occupational 
directivity. Educational practice has some dependencies and other characteristics. Compared to academic graduate students, graduates of professional degrees pay more attention to the improvement of their overall quality and applied knowledge and practical innovation ability in the cultivation process. They aim to cultivate innovative talents to meet the needs of today's social development for applied innovative talents [7]. The innovative practice ability of graduate students is reflected in the innovative ability to solve practical problems in the engineering field based on professional knowledge and skills, reflecting the professionalism and value of a full-time Master of Engineering. Therefore, the full-time Master of Engineering innovation and practical ability consists of scientific research and technology development capability, problem of constructing and problem solving, knowledge integration and information processing ability, communication expression and teamwork ability, project leadership and organization management throughout the innovative thinking and consciousness [8]. Capabilities and other components, of which scientific research and technology development capabilities, construction issues and problem solving capabilities reflect the core capabilities of professional value, knowledge integration and information processing capabilities, communication and teamwork capabilities, project leadership and organizational management capabilities do not depend on professional Strong knowledge, but it plays an important role in solving practical engineering problems. It is a reflection of the overall quality of a full-time master's degree program, and it is also the goal of our efforts and expectations.

\section{Cultivation OF Professional Degree GRADUATES' PRACTICAL AND CREATIVE ABILITY}

With the rapid development of all walks of life in China and the development of artificial intelligence in work distribution, especially the engineering industry urgently needs a large number of specialized talents in high-level engineering fields with innovative application capabilities. The demand for talents in short supply forces the universities to actively explore the whole day. The idea of the training mode for the innovation ability of postgraduates majoring in engineering and engineering degrees to establish a professional training system. How to combine the engineering specialty with the advantages of the school-enterprise cooperation, conducted beneficial explorations in setting up a two-way learning tutor mechanism and optimizing curriculum settings, and achieved good results. It has always been a question to be considered and explored by the instructors of Nanjing university of aeronautics and astronautics [9]. Especially in the new educational environment, the construction of "two-class" has great changes compared with the " 211 " and " 985 " universities. First, the world-class universities and discipline construction programs implement dynamic management. There is no longer tenure, and poor performance is necessary [10]. The second is that regardless of whether they are subordinate colleges or local colleges and universities, as long as they have the advantages and characteristics of the discipline, they all have the opportunity to obtain financial support from the government and improve the strength of running a school. It can be said that the threshold has been eliminated and it is helpful to overcome the problem of dividing the university into three years and six years. Such phenomena; the third is to focus on overall planning and connotation development. In the past, the " 211 " and " 985 " universities mainly provided hardware support for funds, disciplines, equipment, and projects, while the new world-class universities and the firstrate discipline construction overall program also needed to transform teachers, innovative talents, cultural heritage, and achievements. In order to carry out overall planning for more aspects, including the internal governance structure of universities and social participation mechanisms, we must carry out in-depth reforms. Full-time professional graduate degree education is aimed at cultivating a batch of high-level applications that have solid basic theory, broad expertise, good professional qualities, and strong solutions to practical engineering problems, and can independently undertake professional technology or management work. talent [10]. The difference between professional degree graduate students and academic master graduate students is to meet the actual needs of enterprises and society, with the ability of engineering practice, and can quickly become the company's field engineers, design engineers and management engineers of specialized personnel. At present, the proportion of master degree students in various universities and training institutions in China is gradually expanding, and it is close to the ratio of 1:1 with master academic students, and the enrollment scale continues to increase [11]. Professional degree graduate students have become an important form of postgraduate education in China. Taking the training target for masters of engineering majors as an example, it is required to master the basic theories and methods of design of modern related industries, the manufacturing technologies of modern related industries, modern control theories and methods, and the use of maintenance technologies, etc., which require a broad range of knowledge and applications. Practical ability. In order to meet the training requirements for the professional degree master's education in valuing practice and solving practical problems of enterprises, the domestic universities and colleges have generally established a school-enterprise cooperation and dual-teacher training model [12]. Considering that the special master students may have weak foundations due to interdisciplinary issues, the training program requires the selection of undergraduate professional courses and the study of master's degree basic courses; the practice case study and group project cooperation links are strengthened in the course, and comprehensive experiments are designed for innovative design courses. To enhance students' ability lies in applying knowledge. Through the enterprise practice base, enterprise graduate workstations, and teachers' cooperative enterprises, the special master student can participate in the project $R \& D$ practice in the company. Under the joint guidance of university tutors and corporate tutors, ie, the "double-tutor system", the company conducts research and development projects for the actual enterprise and completes dissertations. Colleges and universities have also taken measures to strengthen the construction of a faculty for the cultivation of 
specialized masters, such as employing enterprise engineers to teach and transporting university teachers to the company to perform post-employment exercises. In addition, the special master training also has significant professional characteristics, such as the development of vocational qualification certificates and professional competence. Environmental awareness innovation ability is an improvement on the basis of professional competence. Environmental awareness and innovation require knowledge and skills such as environmental laws and regulations, environmental impacts, and life cycle assessment, as well as the ability to evaluate and take measures to reduce the life cycle environmental impact of products. This is a convergence and enhancement of professional capabilities. Therefore, in the training phase of university-specific master students, we must establish a training system to cultivate the ability of the special masters in environmental awareness innovation through the integration of curriculum, projects, and business practices; in collaborative enterprises, instructors, and management departments, etc. The establishment of safeguard measures to ensure the smooth operation of the training system for innovative environmental awareness, and to achieve a common improvement of professional knowledge and environmental awareness.

In view of the above, the new education environment and the teaching mode are discussed. The cultivation model of the master degree candidate's innovation ability is proposed. The environment awareness innovation training system combining curriculum teaching, project training and enterprise issues is proposed; the support strategies for teachers and management departments for specialized training will focus on the scale and innovation of enterprises, the ability of teachers to instruct engineering teachers, and the construction of practical training bases for management departments. This will undoubtedly promote the training and promotion of innovative talents effect.

\section{PROFESSIONAL DEgREE GRADUATES' PRACTICAL INNOVATION ABILITY}

Full-time graduates of professional degrees are mainly responsible for cultivating a solid theoretical basis and broad professional knowledge of the profession, and at the same time have the ability to solve practical problems. They can undertake professional technical or management work in their respective fields and have high professional qualities. Hierarchical application-oriented professionals. Graduates of full-time professional degree graduates are mainly full-time undergraduate graduates. These students lack professional practice experience and lack of work experience. After graduating, they have to directly face jobs. How to train these students into more than two years the orientation of training objectives for high-level talents who can meet the needs of the society and truly achieve the professional degree training objectives is particularly important. It can neither be separated from reality, nor can it deviate from the professional orientation and the requirements for the training of full-time professional degrees. It must be scientific and feasibility. After related research, analysis and integration, we can consider and implement the research of this project from the following aspects: how to analyze the quality of undergraduates' attention to influence the training quality of professional degrees; how to set reasonable courses under specific training objectives, especially practical courses The setting, etc.; With practical ability as a goal, how to build a joint guidance system for the tutors and tutors outside the school, because the quality of fulltime professional degree training is closely related to tutors, tutors are the key to training talent, and play a crucial role Therefore, the cultivation of instructors is also an important part of the graduate training process. Under the new graduate education environment, with the guidance of cultivating innovative talents, combining the professional master's theoretic learning with practical engineering, the team will explore the training mode of engineering innovation talents based on the requirements of full-time professional degree graduate engineering innovation ability cultivation. To comprehensively improve the quality of personnel training for full-time graduates of professional degrees, we must pay attention to cultivating innovative engineering talents that meet the needs of economic and social development. Investigate and research the factors affecting the quality of full-time professional graduates; The urgent research and research on the cultivation and promotion of the practical ability of full-time professional graduates; The approach and methods of the cultivation of full-time master graduates' innovative consciousness; Based on innovation and practice ability The study of the construction of the evaluation system; relying on joint training grounds or engineering training units, schoolenterprise instructors to cooperate in the exploration of effective models of students' innovative ability.

\section{CONCLUSION}

The preparatory work carried out in this article, including the collection of literature and other related work, has fully understood and understood the innovative ability of postgraduates in the innovation ability based on the professional knowledge and skills to solve practical problems in the engineering field, reflecting the full-time master of engineering Professionalism and value. Full-time master's degree in innovation and practical ability consists of scientific research and technology development capability, problem of constructing and problem solving, knowledge integration and information processing ability, communication expression and team cooperation ability, project leadership and organization management ability, etc. constitute. In the process of teaching and designing full-time Master of Engineering, teaching is generally conducted on questions and projects. There are many kinds of scientific researches and methods, but the basic steps to accomplish them are the same. They mainly include the steps of asking questions and assumptions, designing research programs, implementing research and collecting data, processing analytical data and verifying hypotheses, and deducing conclusions. Logically speaking, scientific research methods include induction-deduction, analysis-synthesis, comparison-classification, abstract-specificity, and proofrebuttal. Of course, the theoretical understanding and application of the cultivation and promotion of innovative talents for full-time masters of engineering must continue to be deepened in subsequent project studies. 


\section{ACKNOWLEDGMENT}

Project is supported by National Natural Science Foundation of China (No. 11232007), Natural Science Foundation of Jiangsu Province (No. BK20130787), the Fundamental Research Funds for the Central Universities (No. NS2014003), Research Fund of Zhejiang Guangchuan Engineering Consulting Co., Ltd (No. Y1704), Research Fund of Graduate Education and Teaching Reform of NUAA(No. 2017-2), Research Fund of Education and Teaching Reform of College of Aerospace Engineering, NUAA(No. 2017-5).

\section{REFERENCES}

[1] D.Q. Zhang, H. Zeng, and H.X. Wang, "Discussion on innovative ability training mode of full-time professional degree postgraduates," Journal of Liaoning University of Technology(Social Science Edition), vol. 18, pp. 96-100, August 2016.

[2] P. Li, L. Ma, and Y. Cai, "Innovation Ability Training System Construction of Full-time Professional Degree Graduate of Control Engineering," Journal of Jiyuan Vocational and Technical College, vol. 11, pp. 81-85, November 2012.

[3] B.K. Gao, X.F. Wang, and W.J. Ren, "Exploration on Full-time Engineering Graduates' Innovation Ability Training Mode," Guide Journal of science and education, vol. 11, pp. 61-62, April 2014.

[4] M.W. Di, D.W. Zhang, and H.Y. Liu, "Exploration and Practice of Innovative Ability Cultivation in Practice for the Full-time Professional Degree Graduate," Guangdong chemical industry, vol. 42, pp. 286-287, July 2015

[5] Y. Qiang, "Exploration of Teaching Innovative Thinking in 'Materials Mechanics'," Three Gorges Higher Education Research, vol. 13, pp. 4445, January 2009.

[6] Y.F. Shen, Y.Z. Xu, and L. Liu, "Combining multiple teaching methods in the teaching of material mechanics to improve students' creative thinking skills," University Education, vol. 15, pp. 146-147, April 2015.

[7] C.C. Liu, Y.F. Shen, and Y.P. Huang, "Thinking and Practice of Cultivating Students' Scientific Thinking Ability in Material Mechanics Teaching," Higher Agricultural Education, vol. 12, pp. 65-67, October 2008.

[8] Z.Q. Long, "Thinking on Teaching Reform and Innovation of Material Mechanics Course, "Light Industry Science and Technology, vol. 18, pp. 158-159, September 2014.

[9] S.Y. Ji, J.J. Wu, and Q. Li, "In the course of "Materials Mechanics' Innovation awareness and practical ability training," Higher Science Education, vol. 7, pp. 90-92, May 2008.

[10] H.C. Quan, G.X. Fang, "Discussion on Cultivating Students' Creative Thinking Method in Material Mechanics Course," Shangxi Architecture, vol. 13, pp. 235-236, May 2016.

[11] G.H. Wu, G.P. Zou, and X.Y. Zhang, "Elementary talk on experiment teaching of material mechanics and cultivation of students' innovative consciousness," Heilongjiang Education(Higher Eduacation Research \& Appraisal), vol. 4, pp. 80-81, April 2011.

[12] F.H. Wang, F. Wei, and W.Y. Yan, "An Attempt to Cultivate Students' Innovative Ability in the Teaching of Material Mechanics and Related Courses." Experimental Technology and Management, vol.24, pp. 201202, October 2007. 